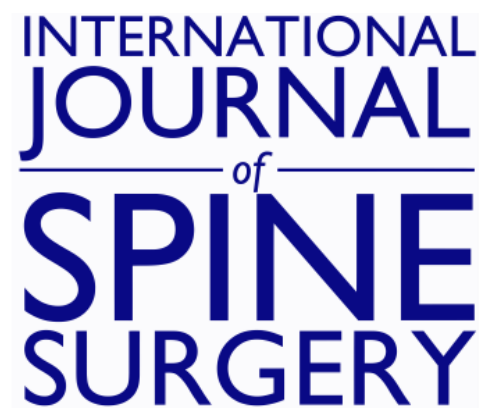

\title{
Decade-Wise Computed Tomography-Based Morphometric Measurements of a Single Lumbar Spinal Motion Segment L4-5
}

\author{
ARVIND G. KULKARNI, SAMEER RUPAREL, SUNILA JAGGI and NIHKIL MURKEY
}

Int J Spine Surg 2020, 14 (5) 795-803

doi: https://doi.org/10.14444/7113

http://ijssurgery.com/content/14/5/795

This information is current as of April 26, 2023.

Email Alerts Receive free email-alerts when new articles cite this article. Sign up at:

http://ijssurgery.com/alerts

The International Journal of Spine Surgery

2397 Waterbury Circle, Suite 1,

Aurora, IL 60504, Phone: +1-630-375-1432 


\title{
Decade-Wise Computed Tomography-Based Morphometric Measurements of a Single Lumbar Spinal Motion Segment L4-5
}

\author{
ARVIND G. KULKARNI, MS, SAMEER RUPAREL, MS, SUNILA JAGGI, MD, NIHKIL MURKEY, MD \\ Bombay Hospital and Medical Research Center, Mumbai, Maharashtra, India
}

\begin{abstract}
Background: A spinal motion segment comprises facet joints and intervertebral disc. A complex interplay of biomechanical factors occurs between them with degeneration giving rise to numerous pathological conditions. We conducted a study to find a correlation between facet joint orientation and intervertebral discs with age.

Methods: A cross-sectional study of 203 consecutive subjects undergoing a computed tomography scan of abdomen and pelvis were included. Subjects were divided into 5 groups based on age (group I: 18-30 years; group II: 3140 years; group III: 41-50 years; group IV: 51-60 years; group V: 61-70 years). Using 3-dimensional reconstruction images, orientation of lumbar facet joints at the L4-5 level was measured. Similarly, adjacent disc heights at L3-4 and L4-5 were measured and their ratio was documented.

Results: The study included 106 males and 97 females. A positive correlation was noted between age and sagittal facet orientation until age 60 years. However, after age 60 years, a negative correlation with age was seen, which was statistically significant. Similarly, the disc height ratios show a progressive decline in their values with age. However, this decline was statistically significant only after age 60 years.

Conclusion: The gradual change of facet joint orientation from sagittal to coronal as the age crosses from 30 to 60 , to beyond 60 , with a simultaneous and parallel diminishing in the disc height probably is one of the attributes of the phenomenon of autostabilization of a motion segment.
\end{abstract}

\section{Biomechanics}

Keywords: facet joint orientation, disc degeneration, degeneration, aging, L4-5, degenerative spondylolisthesis, natural history, computed tomography

\section{INTRODUCTION}

A lumbar spinal motion segment is considered analogous to a tripod consisting of intervertebral disc anteriorly and facet joints on either side posteriorly. Degeneration is an inevitable process affecting all parts of human body and the lumbar spine is no exception to it. It has been proven that aging process of facet joints ${ }^{1-3}$ and that of intervertebral discs ${ }^{4}$ begins as early as the third decade. This gives rise to numerous pathologies later in life and various studies have tried to find out the root cause of these ailments.

According to the Kirkaldy-Willis theory of degeneration, ${ }^{5}$ there exists a stage of instability followed by stability. Various changes within facet joints and intervertebral discs have been postulated to give rise to this degenerative cascade. One of the important by-products of this cascade is change in the facet joint orientation and thus its impact in the development of degenerative spondylolisthesis. Wang et $\mathrm{al}^{6}{ }^{6}$ demonstrated that with increasing age facet joints become more sagittally oriented. However, whether these secondary changes have a role to play in development of instability has not been proven. Also, a correlation between facet joint orientation and intervertebral disc heights is not yet established. We conducted a study to find a correlation between facet joint orientation and intervertebral disc with age and to document its impact on stabilization of the spinal motion segment.

\section{METHODS}

A cross-sectional study to find out a correlation between orientation of facet joints and changes in disc height with aging was conducted between January and October 2017; it was approved by the Institutional Review Board. It was a cohort study in 

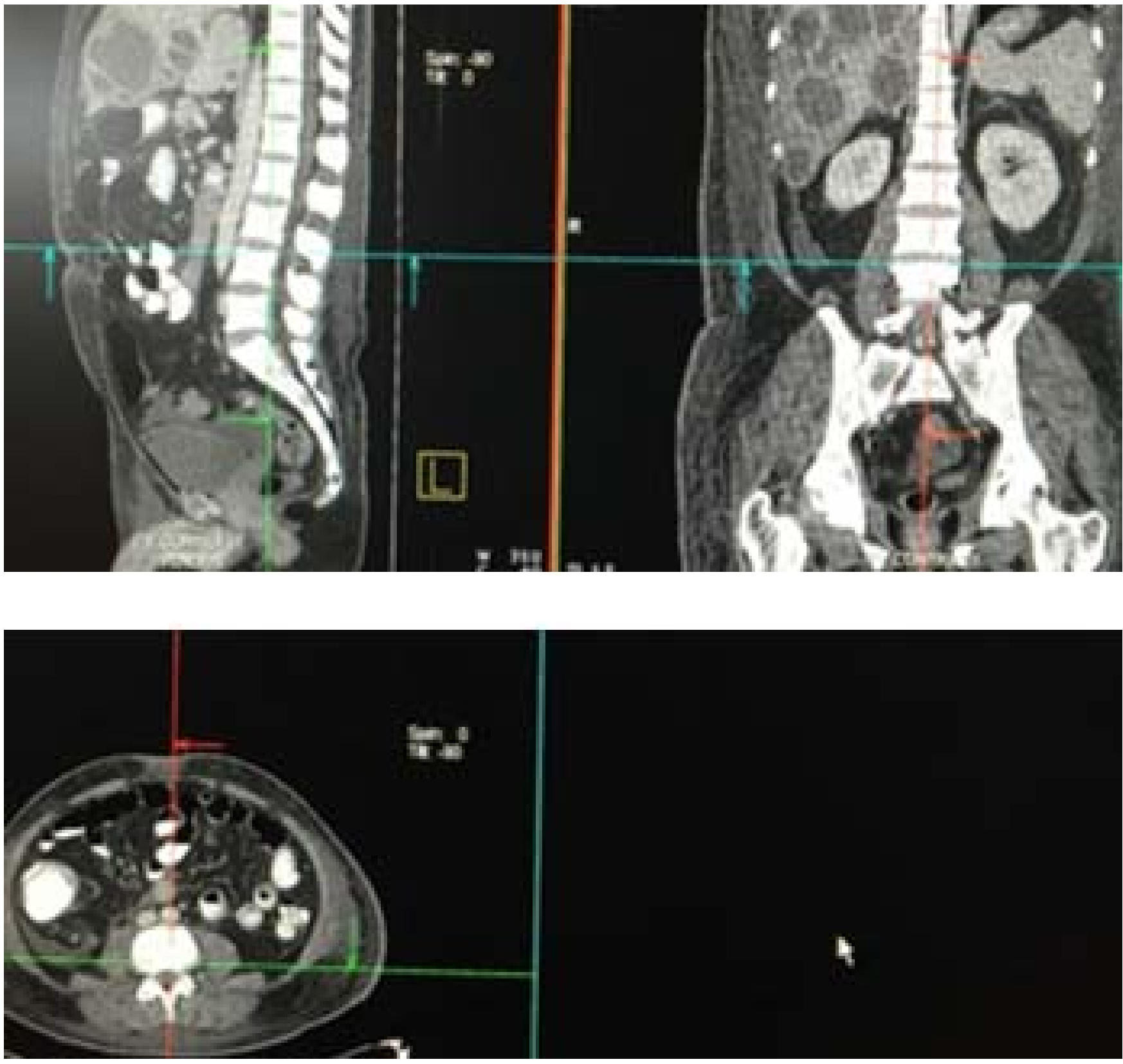

Figure 1. Three-dimensional reconstruction images.

which 203 consecutive subjects undergoing a computed tomography (CT) scan of the abdomen and pelvis for complaints unrelated to the spine were included. Patients aged less than 18 years and more than 70 years were excluded from the study. Those patients having coexistent symptomatic lumbar spinal disorders were also excluded. This was done by asking patients if they had any symptoms related to spinal pathology (one of them being back pain) and clinically examined them. Similarly, if any asymptomatic spinal pathology/deformity was observed on CT scan, these were excluded. The study concentrated on the data collection of a single lumbar spinal motion segment, L4-5, considering that this level is most prone for degeneration, similar to the study by Wang et al. ${ }^{6}$ Data acquisition was done on a 64-slice MDCT scanner with the patient in supine position. Age and sex of the patient was documented. Subjects were divided into 5 groups: group I, 18-30 years; group II, 31-40 years; group III, 41-50 years; group IV, 51-60 years; group V, 61-70 years. Thin axial sections $(1 \mathrm{~mm})$ were made and 3-dimensional reconstruction images were obtained (Figure 1). The images were refor- 


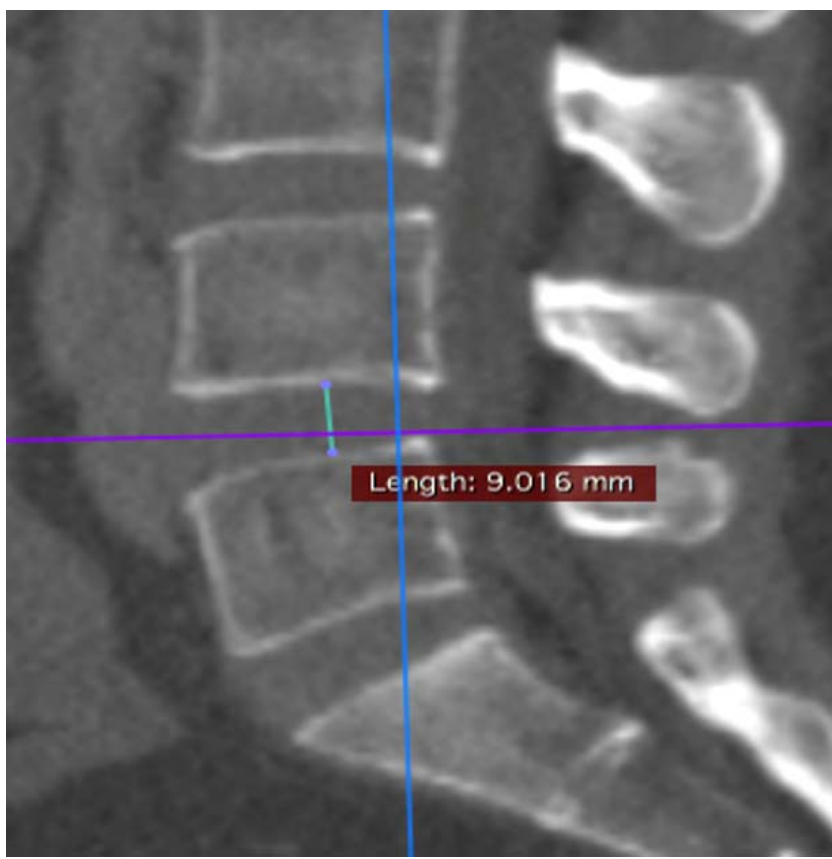

Figure 2. Selection of axial plane for facet joint angle calculation.

matted in midsagittal and axial planes. All images and calculations were made in a bone algorithm for better accuracy.

\section{Calculation of Facet Angles}

For better visualization of lumbar facet joints, an axial section parallel to inferior endplate of L4 and passing through the posterior superior margin of L5 was selected (Figure 2) as described by Canrera et al (see Grobler et $\mathrm{al}^{7}$ ). For calculation of facet joint angles on this axial section, the method described by

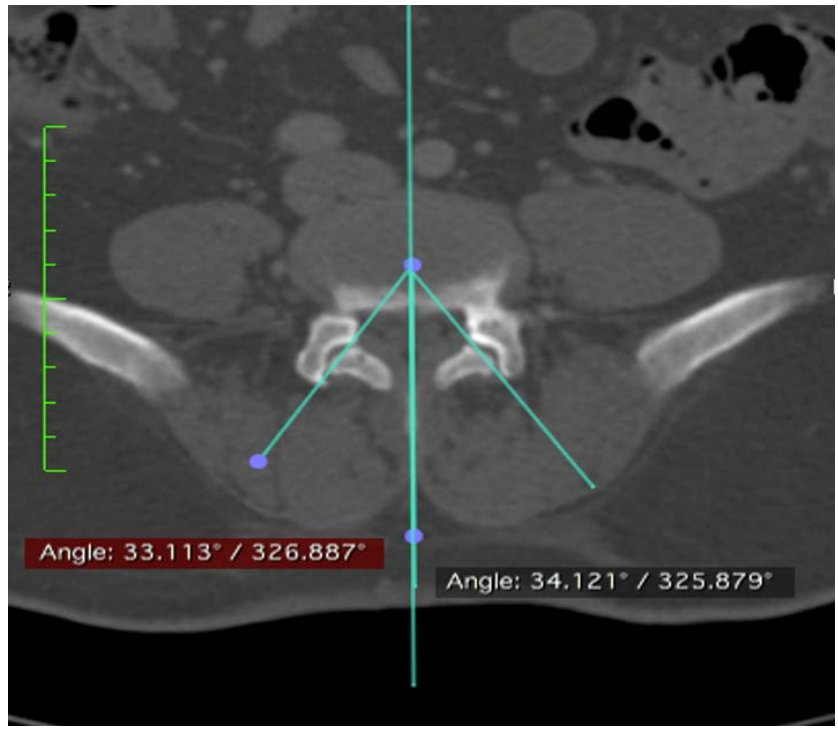

Figure 3. Calculation of facet joint angles.

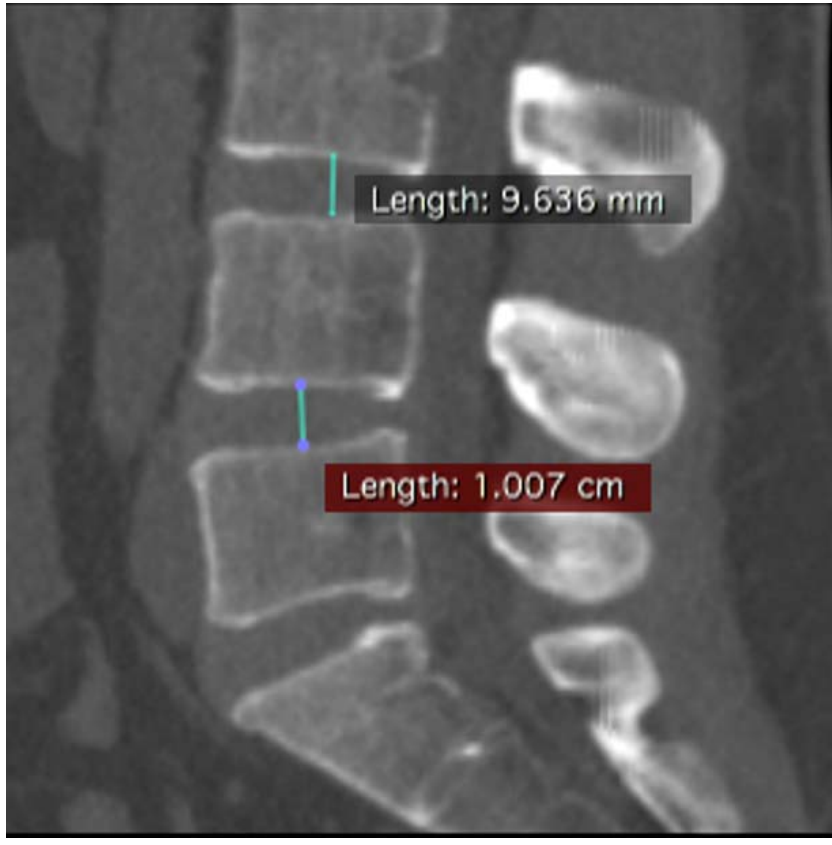

Figure 4. Calculation of disc height at L3-4 and L4-5 levels.

Noren et $\mathrm{al}^{8}$ was adopted. Two lines were drawn: A midsagittal line was drawn through the disc and bisecting base of the spinous process. A facet line was drawn on each side passing between the anteromedial and posterolateral points of each facet. The right and left facet joint angles were calculated between the right and left facet lines and midsagittal line, respectively, and were documented (Figure 3). An average of right and left facet angles were considered as the orientation of facet joints; the smaller the angle, the more sagittally oriented the facet joint.

\section{Calculation of Disc Height Ratio}

To find out the disc height at L4-5 level, midsagittal image of CT scan was considered. The highest point on the concave superior endplate and the deepest point on the concave inferior endplate were marked. A line joining these points was measured and documented as the disc height at the L4-5 level. Disc height at the L3-4 level was also documented following the method described above (Figure 4). For a better understanding of disc degeneration, the ratio of disc heights at L3-4 and L4-5 was calculated.

All measurements were made twice; once by a clinical radiology fellow supervised by a radiologist consultant and again by a clinical spine fellow who was unaware of the hypothesis. 
Table 1. Distribution of subjects: age and sex.

\begin{tabular}{lccc}
\hline & Total Subjects (n) & Males & Females \\
\hline Total study group & 203 & 106 & 97 \\
Group I (18-30 y) & 22 & 10 & 12 \\
Group II (31-40 y) & 35 & 15 & 20 \\
Group III (41-50 y) & 52 & 25 & 27 \\
Group IV (51-60 y) & 36 & 19 & 17 \\
Group V (61-70 y) & 58 & 37 & 21 \\
\hline
\end{tabular}

\section{Statistical Analysis}

To find out the adequate number of subjects required for the study, statistical analysis was done where power of study was $90 \%$ and significance level was $5 \%$. We found a sample size of 181.34 to be sufficient to draw conclusions. Comparison of average facet joint angles between groups and gender was analyzed using a $t$ test. Comparison of disc height ratios between groups was done using the Mann-Whitney test. Analysis of average disc heights between groups (in general, males and females) at L3-4 and L4-5 was performed using a $t$ test. Comparison between the groups and multiple comparisons were conducted using variance analysis and least significant difference, respectively. The correlation analysis was performed with the Pearson method. The criterion for statistical significance was $P<.05$. The intraclass correlation coefficient was calculated to determine the reliability or agreement between the 2 observers for the measurement of facet angle.

\section{RESULTS}

The study included 106 males and 97 females (N $=203)$. The average age of patients was 50.1 years (range, 18-70 years).

The subjects were divided into 5 groups. The total number of subjects in group I (age 18-30 years) was 22 , group II (31-40 years) was 35 , group III (41-50 years) was 52, group IV (51-60 years) was 36 , and Group V (61-70 years) was 58 (Table 1).
Similarly, the number of males and females in group I were 10 and 12 respectively, in group II were 15 and 20, in group III were 25 and 27, in group IV were 19 and 17, and in group V were 37 and 21 (Table 1).

The intraclass correlation coefficient was found to be 0.88 , which shows excellent agreement between the 2 observers for facet angle measurement.

\section{Facet Joint Angles}

The average facet angles (in degrees) in group1 was 45.397, in group II was 41.527, in group III was 41.436 , in group IV was 42.082, and in group V was 44.962 (Table 2).

We did not find any statistically significant difference $(P<.05)$ for average facet angles in different age groups except between groups IV and V.

The average facet angles (in degrees) between males and females in group I were 44.624 and 46.17 respectively; in group II, 42.617 and 40.437; in group III, 41.58 and 41.292; in group IV, 40.641 and 43.532; and in group V, 43.365 and 46.559 (Table 2).

The difference between average facet angles (males and females) was statistically significant ( $P$ $<.05$ ) only in group V. Groups I, II, III, and IV did not report any significant difference in their values $(P>.05)$.

This suggests a significant change in orientation of facet joint angles after age 60 years. Also, on observing, the change is from sagittal to coronal. Similarly, the difference is significant between males and females aged more than 60 years, with females having a coronal orientation.

\section{Facet Tropism}

On comparison of right and left facet joint angles, the difference was plotted as mild $\left(<7^{\circ}\right)$, moderate $\left(8-15^{\circ}\right)$ and severe $\left(>15^{\circ}\right)$. In group 1 , out of 22,17 had mild, 5 had moderate, and none had severe

Table 2. Facet joint angle measurements: average and gender-based distribution.

\begin{tabular}{|c|c|c|c|c|c|}
\hline Group & $\begin{array}{c}\text { Average Facet Joint Angle, } \\
\text { mean } \pm \mathrm{SD},{ }^{\circ}\end{array}$ & $P$ Value ( $t$ test) & $\begin{array}{c}\text { Average Facet Joint } \\
\text { Angles in Males, } \\
\text { mean } \pm \mathrm{SD},^{\circ}\end{array}$ & $\begin{array}{c}\text { Average Facet Joint } \\
\text { Angle in Females, } \\
\text { mean } \pm \mathrm{SD},^{\circ}\end{array}$ & $\begin{array}{c}P \text { Value } \\
\text { (Comparison Between } \\
\text { Males and Females) }(t \text { test })^{\mathrm{a}}\end{array}$ \\
\hline I $(18-30 y)$ & $45.397 \pm 6.97$ & 0.082 (groups I and II) & $44.624 \pm 7.18$ & $46.170 \pm 5.79$ & 0.8966 \\
\hline II $(31-40 y)$ & $41.527 \pm 9.18$ & 0.89 (groups II and III) & $42.617 \pm 9.29$ & $40.437 \pm 11.53$ & 0.9045 \\
\hline III $(41-50 y)$ & $41.436 \pm 7.069$ & 0.7566 (groups III and IV) & $41.58 \pm 7.94$ & $41.292 \pm 5.91$ & 0.6599 \\
\hline IV $(51-60 y)$ & $42.082 \pm 8.89$ & $\mathbf{0 . 0 3 5 7}$ (groups IV and V) & $40.641 \pm 8.36$ & $43.532 \pm 8.386$ & 0.4122 \\
\hline $\mathrm{V}(61-70 \mathrm{y})$ & $44.962 \pm 8.053$ & & $43.365 \pm 6.85$ & $46.559 \pm 6.85$ & 0.0294 \\
\hline
\end{tabular}

${ }^{\mathrm{a} B o l d}$ indicates statistical significance. 
Table 3. Facet joint tropism.

\begin{tabular}{llcccc}
\hline Group & Gender & $\begin{array}{c}\text { Total } \\
\text { Subjects }\end{array}$ & $\begin{array}{c}\text { Mild } \\
\left(<\mathbf{7}^{\circ}\right)\end{array}$ & $\begin{array}{c}\text { Moderate } \\
\left(\mathbf{8}^{\circ}-\mathbf{1 5}^{\circ}\right)\end{array}$ & $\begin{array}{r}\text { Severe } \\
\left(>\mathbf{1 5}^{\circ}\right)\end{array}$ \\
\hline I (18-30 y) & Males & 10 & 6 & 4 & 0 \\
& Females & 12 & 11 & 1 & 0 \\
II (31-40 y) & Males & 15 & 11 & 3 & 1 \\
& Females & 20 & 14 & 5 & 1 \\
III (41-50 y) & Males & 25 & 18 & 4 & 3 \\
IV (51-60 y) & Females & 27 & 20 & 7 & 0 \\
& Males & 19 & 15 & 4 & 0 \\
V (61-70 y) & Females & 17 & 11 & 6 & 0 \\
& Males & 37 & 24 & 10 & 3 \\
& Females & 21 & 17 & 4 & 0 \\
\hline
\end{tabular}

tropism. In group II, 25 subjects had mild, 8 had moderate, and 2 had severe tropism. In group III, 38 subjects had mild, 11 had moderate, and 3 had severe tropism. In group IV, 26 had mild, 10 had moderate, and none had severe tropism. In group $\mathrm{V}$, 41 had mild, 14 had moderate, and 3 had severe tropism (Table 3 ). Thus, out of 203 subjects, only 8 had severe tropism.

On statistical analysis, we did not find significant difference in their values for facet tropism $(P=$ .36804).

\section{Disc Heights at L3-4 and L4-5 With Disc Height Ratios}

The average disc height at the L4-5 level for group I was $10.045 \mathrm{~mm}$; for group II, $9.965 \mathrm{~mm}$; for group III, $10.289 \mathrm{~mm}$; for group IV, $10.335 \mathrm{~mm}$; and for group V, $9.657 \mathrm{~mm}$ (Table 4).

Similarly, average disc height at the L3-4 level for group I was $8.859 \mathrm{~mm}$; for group II, $9.06 \mathrm{~mm}$; for group III, $9.346 \mathrm{~mm}$; for group IV, $9.704 \mathrm{~mm}$; and for group V, $9.652 \mathrm{~mm}$ (Table 4).

The average ratio of disc heights at L4-5 and L3-4 (ie, L4-5:L3-4) was 1.13 for group I, 1.1 for group II, 1.1 for group III, 1.065 for group IV, and 1 for group V (Table 4).

We did not find any statistically significant difference $(P<.05)$ in the average ratio of disc heights between groups except group IVs and V.

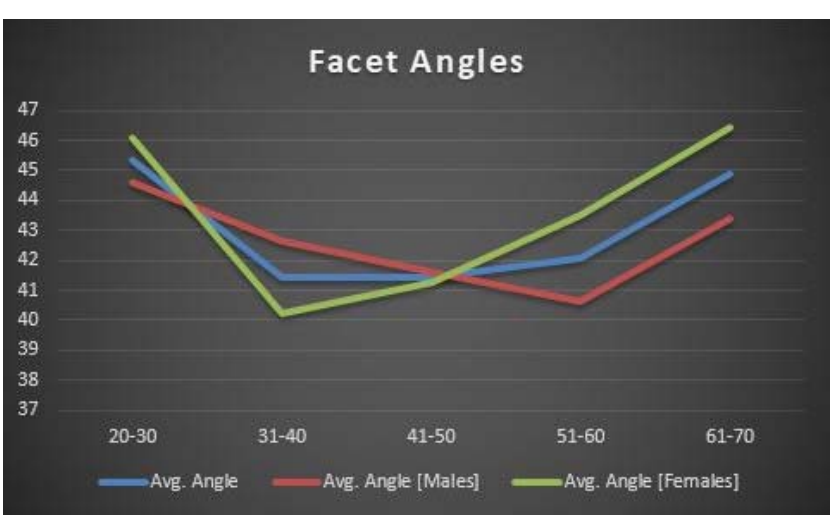

Figure 5. Correlation between facet joint angles and age: average, males, and females.

\section{Correlation of Average Facet Angle with Age}

On plotting a graph to find out a correlation between facet joint angles with age, we found that the joint angles are coronal and stable at a younger age group (Figure 5). They later become sagittal from age groups 30 to 60 years. However, at after age 60 years they return back to their coronal orientation and thus probably become autostabilized. Similar change is noted in both males and females.

\section{Correlation of Average Ratio of Disc Heights With Age}

The graph illustrating a correlation between average disc height ratios and age showed a progressive decline in their values with age in both males and females (Figure 6).

\section{DISCUSSION}

Degeneration of the lumbar spine has always been a topic of interest, discussion, and controversy amongst spine surgeons. These changes give rise to numerous lumbar spinal pathologies like degenerative disc disease, lumbar canal stenosis, and degenerative spondylolisthesis to name a few. An insight into the natural history of these pathologies drives rational preventive care and treatment

Table 4. Disc height measurements at L3-4 and L4-5 with average disc height ratios.

\begin{tabular}{lccc}
\hline Group & $\begin{array}{c}\text { Average Disc Height Ratio } \\
\text { (L4-5:L3-4), mean } \pm \text { SD }\end{array}$ & $\begin{array}{c}\boldsymbol{P} \text { Value } \\
\text { (Mann-Whitney Test) }\end{array}$ & $\begin{array}{c}\text { Average Disc Height at } \\
\text { L4-5 Level, mean } \pm \text { SD, mm }\end{array}$ \\
\hline I (18-30 y) & $1.13 \pm 0.118$ & 0.23 (groups I and II) & $\begin{array}{c}\text { Average Disc Height at } \\
\text { L3-4 Level, mean } \pm \text { SD, mm }\end{array}$ \\
II (31-40 y) & $1.1 \pm 0.128$ & 0.478 (groups II and III) & $9.045 \pm 1.57$ \\
III (41-50 y) & $1.1 \pm 0.171$ & 0.204 (groups III and IV) & $9.965 \pm 1.257$ \\
IV (51-60 y) & $1.065 \pm 0.151$ & $\mathbf{0 . 0 3 6}$ (groups IV and V) & $10.289 \pm 1.61$ \\
V (61-70 y) & $1.0 \pm 0.183$ & & $9.335 \pm 1.546$ \\
& & $9.657 \pm 3.08$ & 1.15 \\
\hline
\end{tabular}

${ }^{\mathrm{a}}$ Bold indicates statistical significance. 


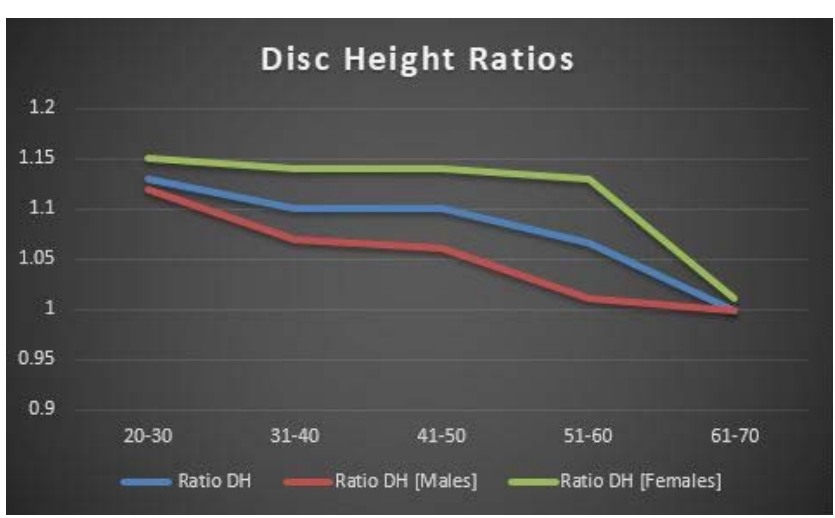

Figure 6. Correlation between disc height ratios and age: average, males, and females.

options. A lumbar spinal motion segment consists of a 3-joint complex, intervertebral disc anteriorly and two facet joints posteriorly. While aging and degeneration is inevitable, these structures are interdependent on each other and thus, pathological changes in the disc causes alterations in the facet joints and vice versa. For example, loss of disc height due to degenerative disc disease increases load on facet joints and may cause alteration in facet joint orientation or subluxation. Sagittal orientation of facet joints has been strongly linked to the development of degenerative spondylolisthesis in numerous studies. ${ }^{9-11}$ Thus, to find out about the natural history of degenerative spinal pathologies, it is very necessary to take into account the changes in both the intervertebral disc and facet joints that occur with aging. Studies considering changes in facet joints with age ${ }^{1-3}$ and intervertebral disc with age ${ }^{4}$ have been seen; however, since it is necessary to consider them both simultaneously for proper inferences, we calculated the changes that occur in lumbar facet joint orientation and disc heights with age. Since, L4-5 is known to be the most common lumbar spinal motion segment affected with degenerative changes, we restricted our study to this level.

A similar study conducted by Wang et $\mathrm{al}^{6}$ found significant differences in the facet joint orientation between all age groups. They concluded that coronal orientation of facet joints negatively correlated with age. Also, they found a linear relationship between these changes. These results are similarly echoed by a recent study documented by Degulmadi et al. ${ }^{12}$ It was a magnetic resonance imaging (MRI)based study of 600 symptomatic patients seeking care for low back pain. They found a positive correlation between age and sagittal facet orienta- tion at all levels from $\mathrm{L} 3$ to $\mathrm{S} 1$ across all age groups. Tropism was noted to be significant at the L5-S1 level, however, not at the L3-4 and L4-5 levels, similar to our study. On correlation of changes in facet joint orientation with age, we found that there was no significant difference between age groups, except age $>60$ years, considered at 10 -year intervals. The reason for this, we consider, is that our study was conducted on asymptomatic subjects. Wang et $\mathrm{al}^{6}$ considered patients following up for periodic physical examination although excluding major lumbar spinal pathological conditions. To exclude confounding bias we considered asymptomatic patients in our study. Similarly, racial factors have been known to affect development of spinal pathological conditions. ${ }^{3,13}$ An important conclusion drawn from the differences in the results is that though facet joint orientation is found to be associated with degenerative spondylolisthesis, it is not the sole factor and numerous factors like sex and weight ${ }^{14,15}$ may be equally responsible for its development. A study by Berlemann et $\mathrm{al}^{16}$ comparing facet joint orientation in patients with degenerative spondylolisthesis and normal subjects concluded that changes in joint angle orientation is a secondary change to degenerative spondylolisthesis rather than a primary one.

Similarly, we did not find a linear relationship in facet joint orientation with age. We found that facet joints were maximally coronal at younger age groups, then later having a sagittal orientation for 3 decades and finally having a coronal and stabilizing orientation at 60 to 70 years of age, correlating with the significant change between groups IV and $\mathrm{V}$ as described above (Figure 5). Though the graphs were not exactly similar when comparing facet joint orientation with age in males and females (Figure 5), they too showed coronal orientation at extremes of age groups. These changes were found to be significant in females aged more than 60 years with a coronal orientation. While conducting the study, we found that numerous subjects aged more than 60 years had a coronal orientation of their facets rather than sagittal. This finding has never been shown in any other study to date. This is better illustrated in Figures 7 and 8 as case example of subjects with age more than 60 years and having a coronal orientation of their facet joints. It has been proven that coronal facet joints are stable and sagittal facet joints are more prone to slip. What would have made these joints relatively stable at age more than 60 years? We 


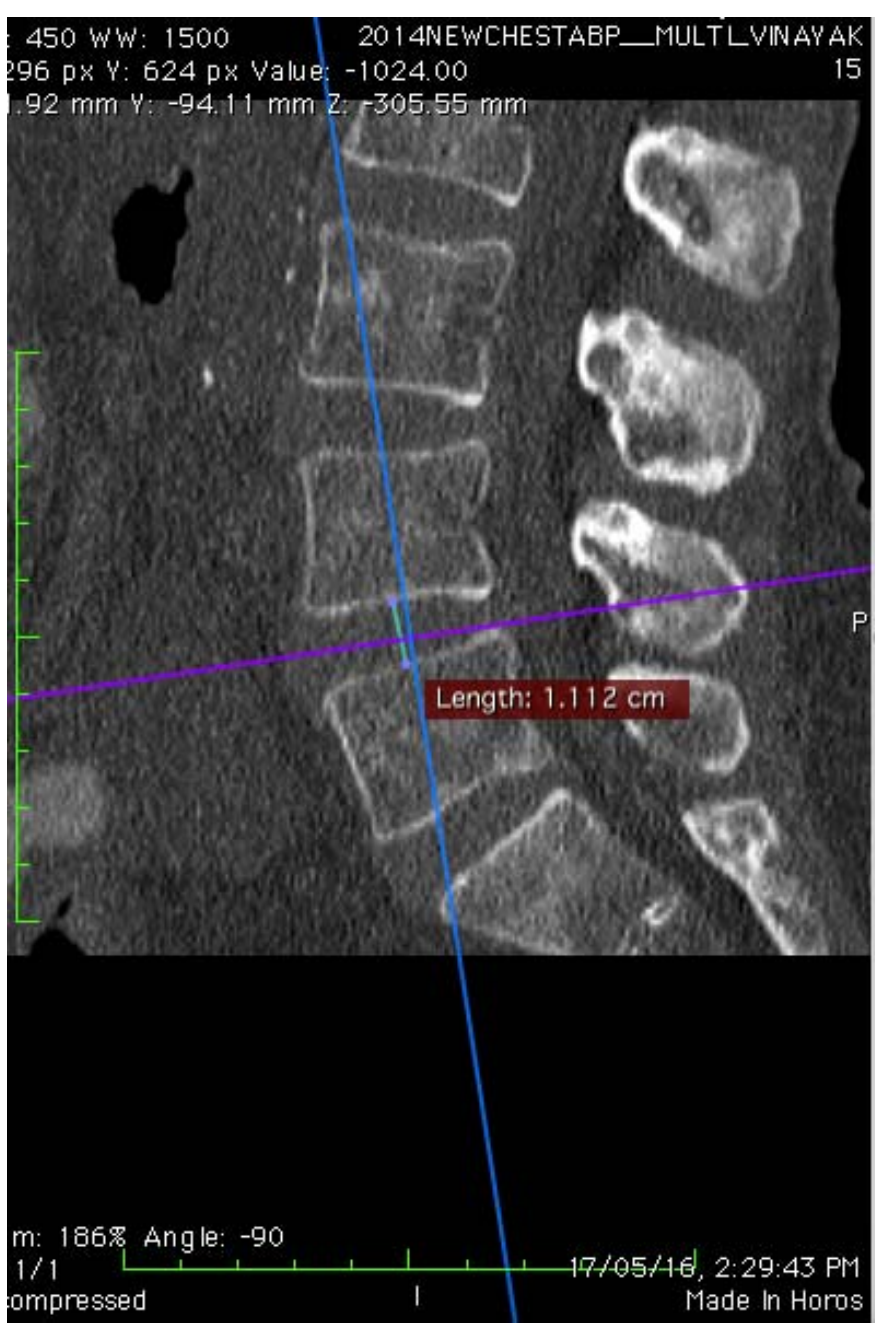

Figure 7. Case example 1, showing coronal facet joint angle at age $>60$ years

believe our findings confirms the Kirkaldy-Willis theory of degeneration, ${ }^{5}$ suggesting autostabilization after a certain age group. To find out what changes would have caused such an autostabilization, we considered the changes in disc height ratios in our study. We found a linear relationship between disc height ratios and age thus suggesting a progressive decline in their disc heights (Figure 6). This pattern was even seen when comparing disc height ratios in males and females (Figure 6). Females aged more than 60 years showed a significant decline in their disc heights at L4-5 level. To eliminate bias and to compare degeneration as the sole cause of reduced disc height at L4-5, these were compared with disc heights at L3-4 and disc height ratios were calculated. We believe that progressive decline in the disc height after a certain point restores the biomechanics of the spinal motion segment, thus off-loading the facet joints and reducing its propensity to slip. Similarly, maximum sagittally oriented facet joints were found

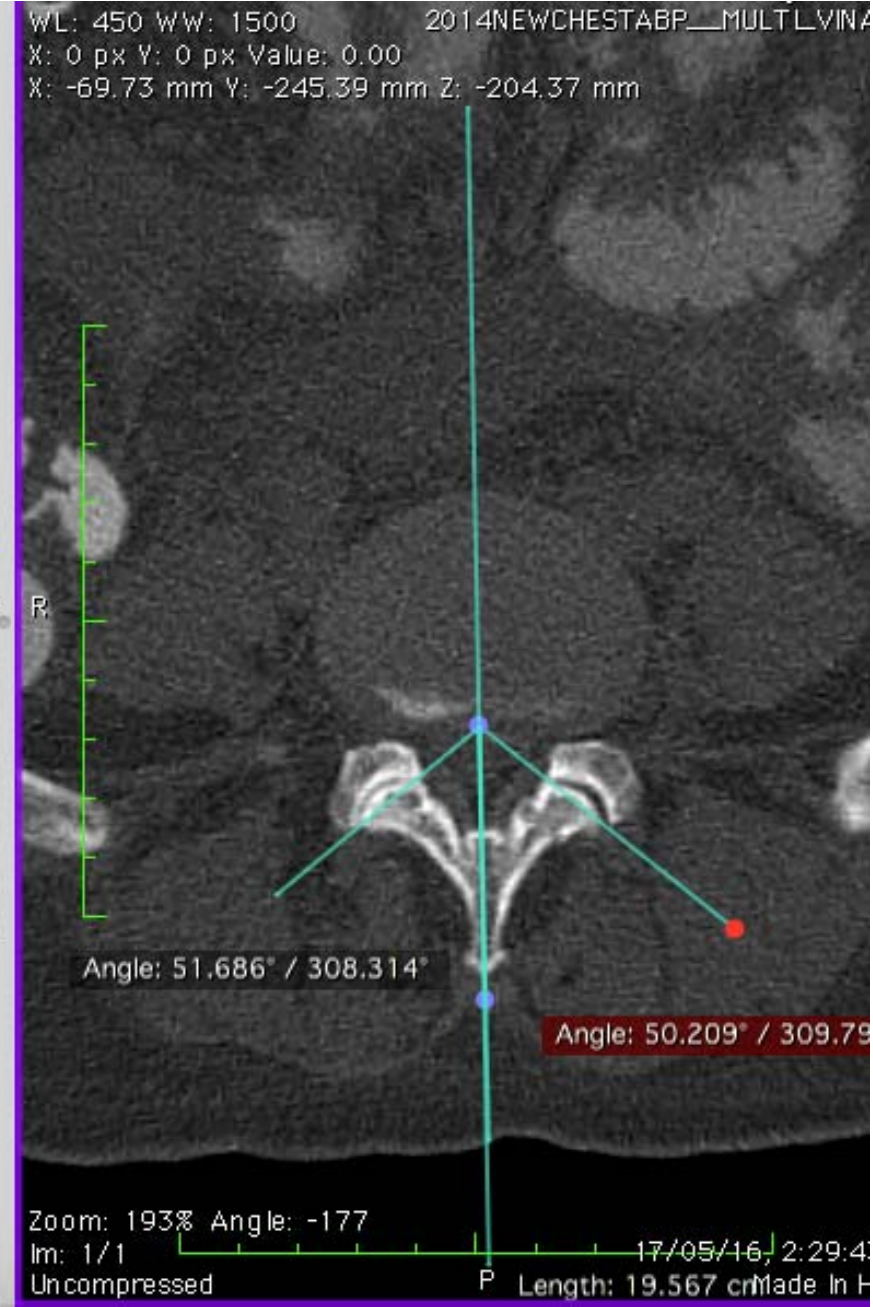

in ages 30 to 60 years; we believe during this period other factors might play a role in already compromised state of facet joints and tip the balance to being pathological and thus development of degenerative spondylolisthesis. Also this is the most common age group found to be affected with degenerative spondylolisthesis. Thus another important conclusion drawn from our study is that mere sagittal orientation of facet joints is not the sole factor for the development of spondylolisthesis.

Our conclusions are further supported by Gong et al. ${ }^{17}$ They compared facet joint angles on CT and MRI of age- and sex-matched symptomatic and asymptomatic individuals. They concluded that facet joint angles showed a statistically significant more sagittal orientation in symptomatic group as compared to the control group. However, on comparing the values of facet joint angles in the control group at L4-5 with our study, there is a similarity of the graph curve. They divided their study group into ages $<40$ 

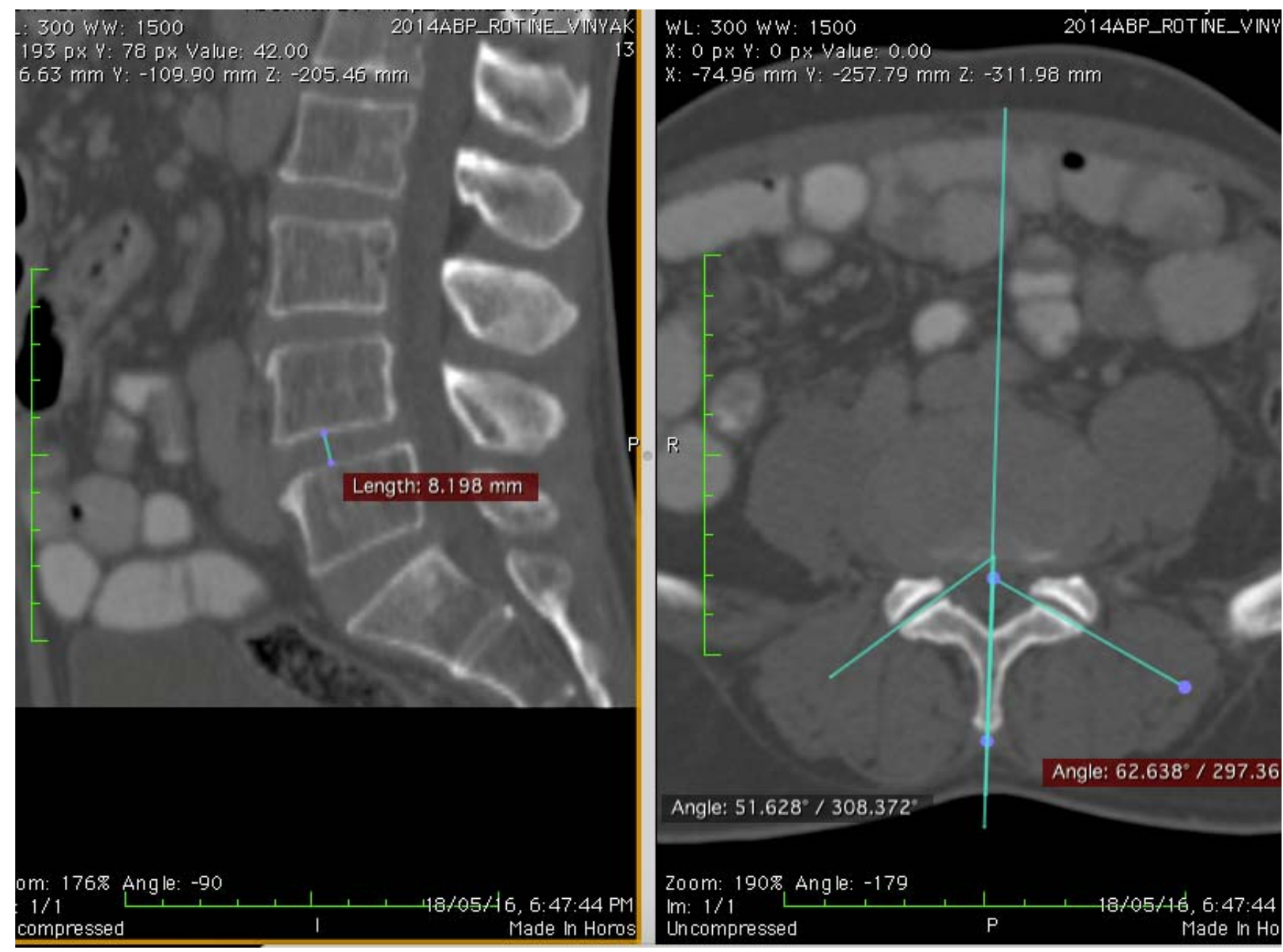

Figure 8. Case example 2, showing coronal facet joint angle at age $>60$ years.

years, 41 to 50 years, 51 to 60 years, 61 to 70 years, and $>70$ years. The facet joint angles were $35.58^{\circ}$, $36.56^{\circ}, 38.63^{\circ}, 40.21^{\circ}$, and $39.28^{\circ}$ respectively. These values also show gradual change in their orientation from sagittal to coronal with increasing age. We are unsure if the angles were coronal to start with since in this study all subjects less than 40 years are grouped as one. In our study, we had 2 separate groups: 18 to 30 years and 31 to 40 years as groups I and II, respectively. However, there is a similar trend of facet joint to become coronal with age in asymptomatic patients at the L4-5 level.

One more interesting observation that is similar between study by Gong et $\mathrm{al}^{17}$ and ours is the sudden alteration of joint angles at age 60 years on comparing values of facet joint angles at L4-5 between symptomatic and asymptomatic subjects. They documented values as follows for the distribution of groups as described above. Symptomatic group values were $34.85,36.21,37.54,35.65$, and
36.23 respectively. In control group, values were $35.58,36.56,38.63,40.21$, and 39.28 respectively. The values remain fairly similar between their groups 1, 2, and 3; however, in group 4 the values are 35.65 and 40.21 for symptomatic and control groups, respectively, illustrating the change that occurs at 60 years. Our study also documented a significant alteration in joint angles from sagittal to coronal and decrease in disc heights after age 60 years. All the above studies did not take disc heights into consideration. We believe significant simultaneous change in values of disc heights and facet angles might not be a coincidence. Further longitudinal studies would be required to prove such hypothesis conclusively.

The limitations of our study include that the study was conducted in asymptomatic individuals. This was done solely with the purpose of eliminating bias for factors other than degeneration and aging. Normal subjects not seeking medical care would 
have been ideal representative sample. However, exposing consenting normal subjects to ionizing radiation was not possible ethically. Hence, we selected the closest representative sample of patients undergoing CT scan of abdomen and pelvis for complaints unrelated to the spine. Secondly, the findings are not statistically significant. This further proves that mere sagittal orientation is not enough for development of pathology and is in sync with the Kirkaldy-Willis theory of degeneration. Interobserver variation in calculation of joint angles and disc heights is a drawback. To minimize this, data were collected by 2 different individuals and an average of these findings was then considered. The study is a CT-based study with images taken in supine position. It does not reflect the changes taking place when the spinal motion segment is mechanically loaded. For a better understanding of disc degeneration, ratio of disc heights L4-5 and L34 was taken. In ideal circumstances, L4-5 disc heights should be compared to disc height of a nondegenerated level. However, since this was not possible, L3-4 was taken into consideration for comparison considering upper lumbar levels tend to degenerate less as compared to lower lumbar levels. Also, disc height loss is only one aspect of disc degeneration. Since ours was a CT-based study, we were not able to grade disc and facet joint degeneration, which may help further to find association between them and joint angles. A longitudinal follow-up with the same cohort of patients would have been the best study from which to draw conclusions.

\section{Conclusion}

The gradual change of facet joint orientation from sagittal to coronal as the age crosses from 30 to 60 , to beyond 60 , with a simultaneous and parallel diminishing in the disc height probably is one of the attributes of the phenomenon of autostabilization of a motion segment.

\section{REFERENCES}

1. Lewin T. Osteoarthritis in lumbar synovial joints. Acta Orthop Scand. 1964;73(suppl):1-112.

2. Fujiwara A, Tamai K, Yamato M, et al. The relationship between facet joint osteoarthritis and disc degeneration of the lumbar spine: an MRI study. Eur Spine J. 1999;8(5):396-401.

3. Eubanks JD, Lee MJ, Cassinelli E, et al. Prevalence of lumbar facet arthrosis and its relationship to age, sex, and race: an anatomic study of cadaveric specimens. Spine (Phila Pa 1976). 2007;32(19):2058-2062.
4. Miller JAA, Schmatz C, Schultz AB. Lumbar disc degeneration: correlation with age, sex, and spine level in 600 autopsy specimens. Spine. 1988;13(2):173-178.

5. Kirkaldy-Willis WH, Wedge JH, Yong-Hing K, et al. Pathology and pathogenesis of lumbar spondylosis and stenosis. Spine (Phila Pa 1976). 1978;3(4):319-328.

6. Wang J, Yang X. Age-related changes in the orientation of lumbar facet joints. Spine (Phila Pa 1976). 2009;34(17):E596-E598.

7. Grobler LJ, Robertson PA, Novotny JE, et al. Etiology of spondylolisthesis. Assessment of the role played by lumbar facet joint morphology. Spine. 1993;18(1):80-91.

8. Noren R, Trafimow J, Andersson GB, et al. The role of facet joint tropism and facet angle in disc degeneration. Spine. 1991;16(5):530-532.

9. Boden SD, Riew KD, Yamaguchi K, et al. Orientation of the lumbar facet joints: association with degenerative disc disease. J Bone Joint Surg [Am]. 1996;78(3):403-411.

10. Sato K, Wakamatsu E, Yoshizumi A, et al. The configuration of the laminas and facet joints in degenerative spondylolisthesis. Spine 1989;14(11):1265-1271.

11. Love TW, Fagan AB, Fraser RD. Degenerative spondylolisthesis. Developmental or acquired? J Bone Joint Surg [Br]. 1999;81(4):670-674.

12. Degulmadi D, Dave BR, Krishnan A. Age- and sexrelated changes in facet orientation and tropism in lower lumbar spine: an MRI study of 600 patients. Eur Spine J. 2019;28(5):961-966.

13. Merrill RK, Kim JS, Leven DM, et al. Differences in fundamental sagittal pelvic parameters based on age, sex, and race. Clin Spine Surg. 2018;31(2):E109-E114.

14. Rosenberg NJ. Degenerative spondylolisthesis-predisposing factors. J Bone Joint Surg [Am]. 1975;57(4):467-474.

15. Sanderson PL, Fraser RD. The influence of pregnancy on the development of degenerative spondylolisthesis. $J$ Bone Joint Surg [Br]. 1996;78(6):951-954.

16. Berlemann U, Jeszenszky DJ, Bühler DW, et al. Facet joint remodeling in degenerative spondylolisthesis: an investigation of joint orientation and tropism. Eur Spine J. 1998;7(5):376-380.

17. Gong GX, Gong DH, Wang H, Auster M. Association of chronic degenerative arthritis related chronic low back pain with altered lumbar facet joint orientation. Radiol Infect Dis. 2019;6(1):15-20.

\section{Disclosures and COI: None.}

Corresponding Author: Dr Arvind G. Kulkarni, Bombay Hospital, Room No. 206, 2nd Floor, New Wing, 12, New Marine Lines, Mumbai, Maharashtra 400020. Phone: 0091-9892875490; Email: drarvindspines@gmail.com.

Published 11 November 2020

This manuscript is generously published free of charge by ISASS, the International Society for the Advancement of Spine Surgery. Copyright (c) 2020 ISASS. To see more or order reprints or permissions, see http://ijssurgery.com. 